\title{
Analysis of multiple frequency excitations of a cracked beam using nonlinear vibrations
}

\author{
M. A. Motamedi ${ }^{1 *}$, Saied Irani ${ }^{2}$ \\ 1* Master of engineering, Faculty of aerospace engineering, K. N. Toosi University of Technology, Tehran, Iran \\ ${ }^{2}$ Assoc. Prof., Faculty of aerospace engineering, K. N. Toosi University of Technology, Tehran, Iran
}

motamedi@email.kntu.ac.ir, $\underline{\text { irani@kntu.ac.ir }}$

\begin{abstract}
In this study, under harmonic multiple frequency excitations, the dynamic response of a cracked cantilever beam is investigated. The breathing crack model is assumed to show the nonlinear behaviour of a transverse crack. The first mode of vibration and the single degree freedom lumped system is considered to simplify the case study. Because of applying the multiple frequency excitations, the analysis is applied in a combinational resonance. Multiple time scales method is employed to solve the motion equation of the crack, and the nonlinear vibrational responses are obtained. Then, by changing the crack parameters and frequency of the excitations, the different dynamic responses of the crack are demonstrated. The proposed model shows that the crack parameters analysis in nonlinear vibration of multiple excitations could be an appropriate method to recognise the crack and the depth of the damage. Results indicate that the beam analysis under multiple frequency excitations is more sensitive than the single frequency excitation to illustrate the impacts of the crack parameters on its vibrational nonlinearity responses.
\end{abstract}

KEYWORDS: Nonlinear vibrations, multiple frequency excitations, breathing crack, perturbation method, structural health monitoring

\section{INTRODUCTION}

Beam-like structures are widely used in most engineering fields. These structures are mostly employed in mechanical, civil, and aerospace engineering. Some examples of beam applications could be in bridges, spar of wings, helicopter turbine blades, and car frames. In general, isotropic materials have extensive usage in the engineering fields (Motamedi \& Hashemi, 2019; Motamedi et al., 2018; Sarbaz et al., 2018). In some cases, we can simplify the analyses by studying these structures as a beam. Damage detection, especially at the primary level, is an essential issue for industries and researchers to avoid catastrophic failure. Crack is one of the main reasons for fracture. Therefore, it is crucial to identify and predict cracks in the earliest possible state.

In order to detect cracks, some researchers have attempted to find a relationship between crack parameters and natural frequency variations. Among researchers who have adopted this kind of approach, we can refer to Narkis (1994); Lee (2016); Khiem and Toan (2014).

Khiem and Tran (2014), in another research, focused on multiple cracks with the approach of changing the natural mode shapes. In another research, Ganjuli and Gouravaraju (2016) have worked on a cantilever beam in order to damage detection applications using mode shapes. Many researchers, however, simulate and analyse cracks in other ways. Some researchers such as Panigrahi and Pohit (2018); Ballo (1998), for instance, have analysed a crack using a spring model. Ballo has used a bilinear stiffness to model the crack stiffness. Another study performed by Curadelli et al. (2008), has used the wavelet transform considering damping effects to detect a crack.

Furthermore, some researchers have modelled stiffness to analyse cracks using the finite element method (Eroglu \& Tufekci, 2016). Dixit and Hanagud (2011) analysed a damaged beam and verified the approach using strain energy-based measuring the damage. Cam et al. (2005) have introduced a vibration strategy to investigate crack detection using the impact of shocks. Other researchers like Friswell and Penny (2002) have indicated that using low frequency in cracked structures could be useful to identify cracks.

In beam structures, Douka et al. (2004) have suggested an approach to identify double cracks utilizing antiresonance effects. In cantilever beams, Jassim et al. (2013) have adopted experimental and theoretical approaches to analyse cracks.

Many researchers like Heydari et al. (2015); Balci and Gundogdu (2017); Bachschmid et al. (2000); Krawczuk and Ostachowicz (1995); Gudmundson (1983); Orhan (2007); Ostachowicz and Krawczuk (1991); Papadopoulos and Dimarogonas (1987); Wu and Law (2004) have utilised the open crack model in their case studies. However, the open crack model cannot display the nonlinear behaviour of cracks. 
Many other researchers like Prawin and Rao (2019); Lengyel and Németh (2018); Carneiro and Ribeiro (2016); Caddemi et al. (2010); Bolotin and Shipkov, (2001); Fu et al. (2018); Cicirello and Palmeri (2014); Giannopoulos et al. (2015); Wauer (1990); Ogam et al. (2014); Liu and Barkey $(2017,2018)$ have considered the nonlinear effect of cracks in their studies using breathing crack model.

Over the last few decades, many researchers proposed nonlinear vibration analysis of the beam in different methods (Ke et al., 2010; Zhang, 2014; Shegokar \& Lal, 2014). In an analysis of a cracked beam under forced vibration, Andreaus and Baragatti (2011) have adopted a numerical approach to investigate the relation between resonances and crack parameters. Liu and Barkey (2017), as well as Andreaus et al. (2007), have analyzed a cracked beam under the single harmonic force and investigated the nonlinear dynamic responses.

Liu and Barkey (2017) introduce a quadratic polynomial model for stiffness to the presentation of the breathing behaviour of the crack. This model shows an appropriate sensitivity to the depth and position of the crack. Because of many advantages of this model, especially the ability to modelling the transient stage between fully opened or fully closed crack, this model has been considered in this work.

In this study, we have analyzed a beam under multiple transverse frequency excitations to get some information about how applying multiple frequency excitations, or preforce could change the nonlinear vibrational response of cracks. Applying multiple frequency excitations leads to some combinational resonances instead of super-harmonic or sub-harmonic resonance. One of these resonances is employed to study the cracked beam's nonlinear behaviours.

To show the cubic and quadratic nonlinearities of a cracked beam, the cubic and quadratic equation of motion are considered. We used the single degree freedom of the Euler-Bernoulli beam. Then we solved the equation of motion using multiple time scales method to reach the nonlinear amplitude-frequency responses of multiple frequency excitations.

\section{SDOF MODELING OF BREATHING CRACK IN A BEAM}

In Fig. 1, a breathing crack model of a cantilever beam is shown. The multiple excitations of $f_{1}(x, t)$ and $f_{2}(x, t)$ applied to the beam's free end. When these harmonic excitations apply to the cracked beam, the breathing crack will be constantly opened and closed with vibration magnitude change per cycle. Fig. 1(b) demonstrates the crack when it is fully opened in tension mode. Fig. 1(c) displays the crack when it is fully closed in compression mode.
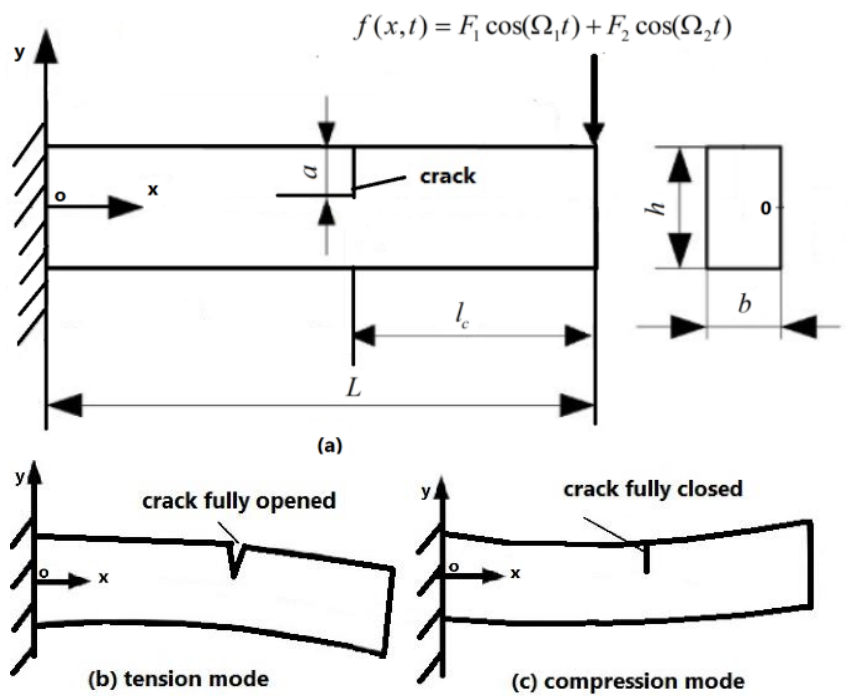

Fig. 1. Model of the breathing crack

As it can be seen, in the process of breathing crack, the stiffness value frequently changes between minimum and maximum in fully opened and fully closed of the crack, respectively. This variable stiffness leads to nonlinearity in vibrational responses.

Based on the beam's B.C. for the cantilever beam, by solving the equation of motion of the Euler-Bernoulli beam, the modal function given by Lalanne et al. (1983):

$$
\begin{aligned}
& \phi(x)=(\cos \lambda x-\cosh \lambda x) \\
& -\frac{(\sin \lambda L-\sinh \lambda L)}{(\cos \lambda L+\cosh \lambda L)}(\sin \lambda x-\sinh \lambda x)
\end{aligned}
$$

The solution to the equation given below is the $\lambda L$ magnitude.

$$
1+\cos (\lambda L) \cosh (\lambda L)=0
$$

The first mode shape of the cantilever beam obtained $\lambda L=1.875$, and in this study, we considered only the first mode. There is no difference of a beam's stiffness value between a vibrating beam and a static. It means that physical properties are the same. When a crack of the beam is in compression mode it means that it is equal to have no crack, so the stiffness of the beam considered as an intact beam that given by Clough and Penzien (1993):

$$
k_{c}=\frac{1}{C_{c}}=\int_{0}^{L} E I \phi^{\prime \prime 2}(x) d x
$$

Where the intact beam's stiffness is $k_{c}, C_{c}$ represents an intact beam's flexibility in state of fully closed of the crack, $E$ is Young's modulus, $I$ is the moment of inertia of cross-section of the beam and beam's modal function is 
$\phi$. It should be noted that due to the presence of crack in a beam, the beam's flexibility increases. In this way, the flexibility of the cracked beam can be written as:

$C_{o}=C_{c}-\Delta C$

Where $\Delta C$ is the additional flexibility because of the crack. Dimarogonas et al. (2013) studied the cracked cantilever beams and determined $\Delta C$ for a crack with the depth of $a$ and $l_{c}$ means the distance between the crack and the free end of the beam.

$\Delta C=\frac{72 \pi L\left(1-v^{2}\right)\left(1-\eta^{2}\right)}{E b h^{4}} \Gamma$

Where $v$ is the Poisson ratio, $\eta=\frac{l_{c}}{L}, L$ is the beam length, $b$ is the width, and $h$ is the height, as indicated in Fig. 1(a). The function of $\Gamma$ is given below (Dimarogonas et al., 2013):

$$
\begin{aligned}
& \Gamma=0.629(\zeta)^{2}-1047(\zeta)^{3}+4.602(\zeta)^{4} \\
& -9.975(\zeta)^{5}+20.295(\zeta)^{6} \\
& -32.993(\zeta)^{7}+47.041(\zeta)^{8} \\
& -40.693(\zeta)^{9}+19.6(\zeta)^{10}
\end{aligned}
$$

Where $\zeta$ equals to $\frac{a}{h}$. Now simply $k_{o}$, that is the stiffness of the beam in the fully opened crack state can be calculated by applying Eq. (7):

$$
k_{o}=\frac{1}{C_{o}}
$$

For modelling the stiffness of the breathing crack, a quadratic polynomial function is considered that is a function of vibration amplitude. So we have (Liu \& Barkey, 2017):

$$
k_{A}=c_{0}+c_{1} \bar{A}+c_{2} \bar{A}^{2}
$$

Where $k_{A}$ is the cracked beam's stiffness, $c_{0}, c_{1}$ and $c_{2}$ are unknown coefficients that are related to the boundary condition of the model that should be calculated. $\bar{A}$ is equal to $\frac{A(t)}{A_{c m}}$. Where $A(t)$ is a time-dependent amplitude of vibration of the crack that is measured from the neutral axis. $A_{c m}$ is the maximum vibration amplitude when the crack is fully closed. Three unknown coefficients 3 after assuming three states of crack for boundary condition are calculated. It is assumed $k_{A}=\frac{\left(k_{o}+k_{c}\right)}{2}$ when $\bar{A}=0, \quad k_{A}=k_{c} \quad$ when $\quad \bar{A}=1, \quad$ and $\quad k_{A}=k_{o}$ when $\bar{A}=-\frac{A_{o}}{A_{c}}$. In these equations $A_{o}$ is the amplitude of vibration from the neutral axis when the crack is fully open and $A_{c}$ is the amplitude of vibration from the neutral axis when the crack is fully open. Now we have (Liu \& Barkey, 2017):

$$
\left\{\begin{array}{l}
c_{0}=\frac{k_{c}+k_{o}}{2} \\
c_{1}=\frac{k_{c}-k_{o}}{2} \frac{A_{o}^{2}+A_{c}^{2}}{A_{o}\left(A_{c}+A_{o}\right)} \\
c_{2}=\frac{k_{c}-k_{o}}{2} \frac{A_{c}\left(A_{o}-A_{c}\right)}{A_{o}\left(A_{c}+A_{o}\right)}
\end{array}\right.
$$

\section{SDOF MODEL OF A BEAM}

Single degree freedom equation of beam under multiple excitations can be indicated as follows:

$$
m^{*} \frac{d^{2} u}{d t^{2}}+2 \psi \omega_{n} \frac{d u}{d t}+K^{*} u=F_{1}^{*}+F_{2}^{*}
$$

Where $u(t)$ is the modal coordinate, which depends on time, $\psi$ is damping, the beam's natural frequency is $\omega_{n}$. $m^{*}, K^{*}$ and $F_{1,2}{ }^{*}$ are the generalized mass, generalized stiffness, and generalized forces, respectively. They are calculated from the following equations:

$$
\left\{\begin{array}{c}
m^{*}=\rho S \int_{0}^{L} \phi^{2}(x) d x \\
K^{*}=E I \int_{0}^{L} \frac{\partial^{4} \phi(x)}{\partial^{4} x} \phi(x) d x \\
F_{1}^{*}=F_{1} \cos \left(\Omega_{1} t\right) \int_{0}^{L} \phi(x) \delta(x-l) d x \\
F_{2}^{*}=F_{2} \cos \left(\Omega_{2} t\right) \int_{0}^{L} \phi(x) \delta(x-l) d x
\end{array}\right.
$$

Because of many variables that effect on the vibration magnitude of the system, the parameters and loads are 
normalized during analysis. Therefore, for the amplitude of vibration in fully opened and fully closed states, we have:

$$
\left\{\begin{array}{l}
A_{c}=\frac{F_{1}^{*}+F_{2}^{*}}{k_{c}} \\
A_{o}=\frac{F_{1}^{*}+F_{2}^{*}}{k_{o}}
\end{array}\right.
$$

\section{MULTIPLE FREQUENCY EXCITATIONS}

The general nonlinear equation of motion of the SDOF beam is:

$$
\begin{aligned}
& \frac{d^{2} u}{d t^{2}}+2 \psi \omega_{n} \frac{d u}{d t}+\omega_{n}{ }^{2} u \\
& +\alpha u^{2}+\beta u^{3}=F_{1} \cos \left(\Omega_{1} t\right)+F_{2} \cos \left(\Omega_{2} t\right)
\end{aligned}
$$

In this equation, $F_{i}(t)$ is considered harmonic with the frequency of $\Omega_{i}$. For considering the damping effect on the system, $\psi$ is considered as a weak linear viscous damping. In this equation, $\alpha$ shows the quadratic nonlinearities coefficient. Furthermore, $\beta$ indicates the cubic nonlinearities coefficient. $\omega_{n}$ is introduced for the magnitude of the natural frequency of the beam with crack. $\omega_{n}, \alpha, \beta$ and $F_{i}(t)$ are obtained from the following equations (Liu \& Barkey, 2017):

$$
\left\{\begin{array}{l}
\omega_{n}=\frac{K_{o}+K_{c}}{2 m^{*}} \\
\alpha=\frac{K_{c}-K_{o}}{2 A_{c \max } m^{*}} \frac{K_{o}{ }^{2}+K_{c}{ }^{2}}{K_{c}\left(K_{c}+K_{o}\right)} \\
\beta=\frac{K_{c}-K_{o}}{2 A_{c \text { max }}{ }^{2} m^{*}} \frac{\left(K_{c}-K_{o}\right) K_{o}}{K_{c}\left(K_{c}+K_{o}\right)} \\
F_{i}(t)=\frac{F_{i} *}{m^{*}} \quad i=1,2
\end{array}\right.
$$

In this study for solving the equation, we applied the multiple scales method. Multiple time scales method is one of the subsequences of perturbation methods. Let (Nayfeh, 2011):

$$
\begin{aligned}
& u(t, \varepsilon)=u_{0}\left(T_{0}, T_{1}, T_{2}\right)+\varepsilon u_{1}\left(T_{0}, T_{1}, T_{2}\right) \\
& +\varepsilon^{2} u_{2}\left(T_{0}, T_{1}, T_{2}\right)
\end{aligned}
$$

The parameters of $u_{0}\left(T_{0}, T_{1}, T_{2}\right), u_{1}\left(T_{0}, T_{1}, T_{2}\right)$, and $u_{2}\left(T_{0}, T_{1}, T_{2}\right)$ are functions that should be determined and $\varepsilon$ is a small dimensionless perturbation parameter. The multiple scales method of perturbation can changes various time scales into an independent time scales like $T_{n}$. It is given by (Nayfeh, 2011):

$T_{n}=\varepsilon^{n} t \quad n=0,1,2 \ldots$

The D-operator can be used (Nayfeh, 2011) to write the first- and second-order derivatives at the equations of motion:

$$
\left\{\begin{array}{l}
\frac{d}{d t}=D_{0}+\varepsilon D_{1}+\varepsilon^{2} D_{2}+\ldots \\
\frac{d^{2}}{d t^{2}}=D_{0}^{2}+2 \varepsilon D_{0} D_{1}+\varepsilon^{2}\left(2 D_{0} D_{2}+D_{1}^{2}\right)+\ldots
\end{array}\right.
$$

Because of ordered categories in multiple scales method, parameters in the equation of motion need to be ordered. To satisfy this, the following terms are selected (Liu \& Barkey, 2017):

$$
\psi=\varepsilon^{2} \psi, \alpha=\varepsilon \alpha, \beta=\varepsilon^{2} \beta
$$

Substituting Eq. (18) into Eq. (13) yields to:

$$
\begin{aligned}
& \frac{\partial^{2} u}{\partial t^{2}}+2 \psi \omega_{n} \frac{\partial u}{\partial t}+\omega_{n}^{2} u \\
& +\alpha \varepsilon u^{2}+\beta \varepsilon^{2} u^{3}=F_{1} \cos \left(\Omega_{1} t\right)+F_{2} \cos \left(\Omega_{2} t\right)
\end{aligned}
$$

Substituting Eq. (15) and Eq. (17) into Eq. (19) we have:

$$
\begin{aligned}
& {\left[D_{0}^{2}+2 \varepsilon D_{0} D_{1}+\varepsilon^{2}\left(2 D_{0} D_{2}+D_{1}^{2}\right)\right] u_{0}} \\
& +\varepsilon\left[D_{0}^{2}+2 \varepsilon D_{0} D_{1}\right] u_{1}+\varepsilon^{2} D_{0}^{2} u_{2} \\
& +2 \varepsilon^{2} \zeta \omega_{n} D_{0} u_{0}+\omega_{n}^{2}\left(u_{0}+\varepsilon u_{1}+\varepsilon^{2} u_{2}\right) \\
& +\varepsilon \alpha\left[u_{0}^{2}+2 \varepsilon u_{0} u_{1}\right]+\varepsilon^{2} \beta u_{0}^{3}= \\
& F_{1} \cos \left(\Omega_{1} t\right)+F_{2} \cos \left(\Omega_{2} t\right)
\end{aligned}
$$

Separating the terms of $\varepsilon^{0}, \varepsilon^{1}, \varepsilon^{2}$ applying Eq. (20) yields to:

$$
\begin{aligned}
& \varepsilon^{0}: D_{0}^{2} u_{0}+\omega_{n}{ }^{2} u_{0}=F_{1} \cos \left(\Omega_{1} t\right)+F_{2} \cos \left(\Omega_{2} t\right) \\
& \varepsilon^{1}: D_{0}^{2} u_{1}+\omega_{n}{ }^{2} u_{1}=-2 D_{0} D_{1} u_{0}-\alpha u_{0}^{2}
\end{aligned}
$$


International Journal of Advanced Engineering, Sciences and Applications (IJAESA), Volume 1, Issue 1, January 2020

$$
\begin{gathered}
\varepsilon^{2}: D_{0}^{2} u_{2}+\omega_{n}{ }^{2} u_{2}=-2 D_{0} D_{1} u_{1}-2 D_{0} D_{2} u_{0} \\
-D_{1}^{2} u_{0}-2 \xi \omega_{n} D_{0} u_{0}-2 \alpha u_{0} u_{1}-\beta u_{0}^{3}
\end{gathered}
$$

The general solution of Eq. (21) is in the following form: $u_{0}=A\left(T_{1}, T_{2}\right) e^{i \omega_{n} T_{0}}+f_{1} e^{i \Omega_{1} T_{0}}+f_{2} e^{i \Omega_{2} T_{0}}+c c$

$$
f_{1}=\frac{F_{1}}{2\left(\omega_{n}{ }^{2}-\Omega_{1}{ }^{2}\right)} \quad f_{2}=\frac{F_{2}}{2\left(\omega_{n}^{2}-\Omega_{2}{ }^{2}\right)}
$$

In Eq. (24), $A$ is the complex magnitude. These are unknown amplitudes. By eliminating the secular terms of $\mathrm{u}_{1}$ the amplitude can be solved as follows:

$$
D_{1} A=0 \quad \text { or } \quad A=A\left(T_{2}\right)
$$

By solving the Eq. (22), $u_{1}$ is found as:

$$
\begin{aligned}
& u_{1}=\frac{1}{3}\left[\alpha \left(-3\left(\frac{1}{2} \Omega_{1}+\omega_{n}\right)\left(-2 \Omega_{2}+\omega_{n}\right)\left(\frac{-1}{2} \Omega_{2}+\omega_{n}\right)\right.\right. \\
& \left(\frac{1}{2} \Omega_{2}+\omega_{n}\right)\left(2 \Omega_{1}+\omega_{n}\right)\left(\Omega_{1}+\Omega_{2}+\omega_{n}\right) \\
& \left(2 \Omega_{2}+\omega_{n}\right) \Omega_{2}\left(-\Omega_{1}-\Omega_{2}+\omega_{n}\right) f_{1} \omega_{n}^{2} \bar{A} \\
& \left(-2 \Omega_{1}+\omega_{n}\right) e^{-i\left(\omega_{n}-\Omega_{1}\right) T_{0}} \\
& +\left(\frac{-1}{2} \Omega_{1}+\omega_{n}\right)\left(-3\left(\frac{1}{2} \Omega_{1}+\omega_{n}\right)\left(-2 \Omega_{2}+\omega_{n}\right)\right. \\
& \Omega_{1} f_{2}\left(\frac{1}{2} \Omega_{2}+\omega_{n}\right)\left(2 \Omega_{1}+\omega_{n}\right) \\
& \left(\Omega_{1}+\Omega_{2}+\omega_{n}\right)\left(2 \Omega_{2}+\omega_{n}\right)\left(-\Omega_{1}-\Omega_{2}+\omega_{n}\right) \\
& \omega_{n}^{2} \bar{A}\left(-2 \Omega_{2}+\omega_{n}\right) e^{-i\left(\omega_{n}-\Omega_{2}\right) T_{0}} \\
& +\left(3\left(-2 \Omega_{2}+\omega_{n}\right) A\left(\frac{1}{2} \Omega_{2}+\omega_{n}\right)\left(2 \Omega_{1}+\omega_{n}\right)\right. \\
& \left(\Omega_{1}+\Omega_{2}+\omega_{n}\right)\left(2 \Omega_{2}+\omega_{n}\right) \\
& \Omega_{2}\left(-\Omega_{1}-\Omega_{2}+\omega_{n}\right) f_{1} \omega_{n}^{2}\left(-2 \Omega_{1}+\omega_{n}\right) e^{i\left(\omega_{n}-\Omega_{1}\right) T_{0}} \\
& +\left(\frac{1}{2} \Omega_{1}+\omega_{n}\right) \Omega_{1}\left(3 \omega_{n}^{2} A f_{2}\left(-2 \Omega_{2}+\omega_{n}\right)\left(2 \Omega_{2}+\omega_{n}\right)\right. \\
& \left(-2 \Omega_{1}+\omega_{n}\right)\left(2 \Omega_{1}+\omega_{n}\right) \\
& \left(\Omega_{1}+\Omega_{2}+\omega_{n}\right)\left(-\Omega_{1}-\Omega_{2}+\omega_{n}\right) e^{i\left(\omega_{n}+\Omega_{2}\right) T_{0}} \\
& \left.+\left(\frac{1}{2} \Omega_{2}+\omega_{n}\right) \ldots+\ldots\right] \div\left[\left(\frac{1}{2} \Omega_{1}+\omega_{n}\right)\right. \\
& \left(-2 \Omega_{2}+\omega_{n}\right)\left(-\frac{1}{2} \Omega_{1}+\omega_{n}\right) \Omega_{1}\left(-\frac{1}{2} \Omega_{2}+\omega_{n}\right) \\
& \left(\frac{1}{2} \Omega_{2}+\omega_{n}\right)\left(2 \Omega_{1}+\omega_{n}\right)\left(\Omega_{1}+\Omega_{2}+\omega_{n}\right)\left(2 \Omega_{2}+\omega_{n}\right) \\
& \left.\Omega_{2}\left(-\Omega_{1}-\Omega_{2}+\omega_{n}\right) \omega_{n}^{2}\left(-2 \Omega_{1}+\omega_{n}\right)\right] \\
& (-2)
\end{aligned}
$$

Substituting Eq. (24) and Eq. (26) into Eq. (23), the equation becomes

$$
\begin{aligned}
& D_{0}^{2} u_{2}+\omega_{n}^{2} u_{2}=2 i A^{\prime} \omega_{n} e^{i \omega_{n} T_{0}}+2 i \bar{A}^{\prime} \omega_{n} e^{-i \omega_{n} T_{0}} \\
& -2 \zeta \omega_{n}\left(i A \omega_{n} e^{i \omega_{n} T_{0}}+i f_{1} \Omega_{1} e^{i \Omega_{1} T_{0}}+i f_{2} \Omega_{2} e^{i \Omega_{2} T_{0}}+c c\right) \\
& -\left[\frac { 2 } { 3 } \left(\alpha^{2}\left(A e^{i \omega_{n} T_{0}}+f_{1} e^{i \Omega_{1} T_{0}}+f_{2} e^{i \Omega_{2} T_{0}}+c c\right)\right.\right. \\
& \left(-3\left(\frac{1}{2} \Omega_{1}+\omega_{n}\right)\left(-2 \Omega_{2}+\omega_{n}\right)\left(-\frac{1}{2} \Omega_{2}+\omega_{n}\right)\right. \\
& \left(\frac{1}{2} \Omega_{2}+\omega_{n}\right)\left(2 \Omega_{1}+\omega_{n}\right)\left(\Omega_{1}+\Omega_{2}+\omega_{n}\right)\left(2 \Omega_{2}+\omega_{n}\right) \Omega_{2} \\
& \left(-\Omega_{1}-\Omega_{2}+\omega_{n}\right) f_{1} \omega_{n}{ }^{2} \bar{A}\left(-2 \Omega_{1}+\omega_{n}\right) e^{-i\left(\omega_{n}-\Omega_{1}\right) T_{0}} \\
& +\left(-\frac{1}{2} \Omega_{1}+\omega_{n}\right)\left(-3\left(-\frac{1}{2} \Omega_{1}+\omega_{n}\right)\left(-2 \Omega_{2}+\omega_{n}\right)\right. \\
& \left(-\frac{1}{2} \Omega_{2}+\omega_{n}\right)\left(\frac{1}{2} \Omega_{2}+\omega_{n}\right)\left(2 \Omega_{1}+\omega_{n}\right) \\
& \left(\Omega_{1}+\Omega_{2}+\omega_{n}\right)\left(2 \Omega_{2}+\omega_{n}\right)\left(-\Omega_{1}-\Omega_{2}+\omega_{n}\right) \\
& \omega_{n}^{2} \bar{A}\left(-2 \Omega_{1}+\omega_{n}\right) e^{-i\left(\omega_{n}-\Omega_{1}\right) T_{0}} \\
& +\left(3\left(-2 \Omega_{2}+\omega_{n}\right) A\left(\frac{1}{2} \Omega_{2}+\omega_{n}\right)\left(2 \Omega_{1}+\omega_{n}\right)\right. \\
& \left(\Omega_{1}+\Omega_{2}+\omega_{n}\right)\left(2 \Omega_{2}+\omega_{n}\right) \Omega_{2}\left(-\Omega_{1}-\Omega_{2}+\omega_{n}\right) \\
& \left.f_{1} \omega_{n}^{2}\left(-2 \Omega_{1}+\omega_{n}\right) e^{i\left(\omega_{n}+\Omega_{1}\right) T_{0}}+\ldots\right] \div \\
& {\left[\left(\frac{1}{2} \Omega_{1}+\omega_{n}\right)\left(-2 \Omega_{2}+\omega_{n}\right)\left(-\frac{1}{2} \Omega_{1}+\omega_{n}\right) \Omega_{1}\right.} \\
& \left(-\frac{1}{2} \Omega_{2}+\omega_{n}\right)\left(\frac{1}{2} \Omega_{2}+\omega_{n}\right)\left(2 \Omega_{1}+\omega_{n}\right) \\
& \left(\Omega_{1}+\Omega_{2}+\omega_{n}\right)\left(2 \Omega_{2}+\omega_{n}\right) \\
& \left.\Omega_{2}\left(-\Omega_{1}-\Omega_{2}+\omega_{n}\right) \omega_{n}^{2}\left(-2 \Omega_{1}+\omega_{n}\right)\right]
\end{aligned}
$$

In Eq. (27) there are some phases that lead to secular terms. Some of them are primary resonance that should be considered anyway. Some are single frequency secular terms and others are the combinations of multiple frequencies. In this study, because of discussion about multi-frequencies we consider one of the combinational resonance secular terms. This term is:

$\Omega_{1}+\Omega_{2}-\omega_{n}=\omega_{n}$

To eliminating the secular terms, we assumed a perturbation in the following form: 
$\Omega_{1}+\Omega_{2}=2 \omega_{n}+\varepsilon \sigma$

Where $\sigma$ is called detuning frequency that used to illustrate the nearness of $\Omega_{1}+\Omega_{2}$ to $2 \omega_{n}$ quantitatively. In this study, $\varepsilon$ assumed to be equal to 0.01 . So the term of $\varepsilon \sigma$ has a very small magnitude. For example, it $\sigma$ illustrates the magnitude of $100 \mathrm{rad} / \mathrm{sec}$, by multiplying $\varepsilon$, it gives $1 \mathrm{rad} / \mathrm{sec}$ magnitude. It is assumed that:

$$
A=\frac{1}{2} a e^{i \theta}
$$

Where $a$ and $\theta$ are real terms. For keep solving process we assumed:

$\gamma=\sigma T_{1}-\theta$

After assuming the steady-state condition during solving problem $\left(\gamma^{\prime}=0\right.$ and $\left.a^{\prime}=0\right)$, and with some mathematical techniques, solving process leads to the following equation:

$$
\begin{aligned}
& \left(\frac{-46 a \sigma+\frac{3}{8} \beta a^{3}-0.1 \alpha^{2} a^{3}}{-3 a F_{1} F_{2} \beta+0.004 \alpha^{2} F_{1} F_{2} a}\right)^{2}+ \\
& \left(\frac{8464 \xi a}{-3 a F_{1} F_{2} \beta+0.004 \alpha^{2} F_{1} F_{2} a}\right)^{2}=1
\end{aligned}
$$

This equation explains the relationship between two main parameters of vibrational amplitude $(a)$ and detuning parameter $(\sigma)$. Now if detuning parameters plot versus amplitude, by the change of crack parameters and excitations properties, the effect of these variables on nonlinear dynamic responses in the presence of the breathing crack could be shown.

\section{RESULTS AND DISCUSSION}

A cantilever beam has been considered with material properties listed in Table 1. Beam dimensions are given in Table 2.

Table 1. Beam material properties

\begin{tabular}{lc}
\hline & Measure \\
\cline { 2 - 2 } Young's modulus $(\mathrm{E})(\mathrm{Pa})$ & $200 \mathrm{e} 9$ \\
Mass density $\rho_{(\mathrm{kg} / \mathrm{m} 3)}$ & 7860 \\
Poisson's ratio $v$ & 0.3 \\
\hline
\end{tabular}

Table 2. Beam dimensions

\begin{tabular}{lc}
\hline & Measure \\
\cline { 2 - 2 } Length $(\mathbf{L})(\mathrm{mm})$ & 1850 \\
Height $(\mathbf{h})(\mathrm{mm})$ & 120 \\
Width $(\mathbf{b})(\mathrm{mm})$ & 150
\end{tabular}

By plotting detuning frequency versus amplitude, the nonlinear responses are shown. In this section, the change of crack parameters such as crack position $(\eta)$, crack depth $(\zeta)$, and damping ratio $(\psi)$ are studied. Furthermore, changing force magnitude and frequencies as well as the stable solutions compared to each other to show softening phenomenon and nonlinearities behaviour have been studied.

As can be seen in Fig. 2, by changing the position of the crack and getting close to the fixed end, the nonlinearity has been increased. Fig. 3 illustrates the effect of damping on nonlinear responses. It illustrates that by increasing the damping ratio, the amplitude of vibration decreases in the absolute magnitude of detuning frequency. Fig. 4 indicates the impact of changing the depth of the crack. By increasing the crack depth, the dynamic responses behave more nonlinear. In Fig. 5, the impact of force magnitude on the frequency curve is shown. The changes lead to increase amplitude in an absolute detuning frequency that can be seen in the figure.

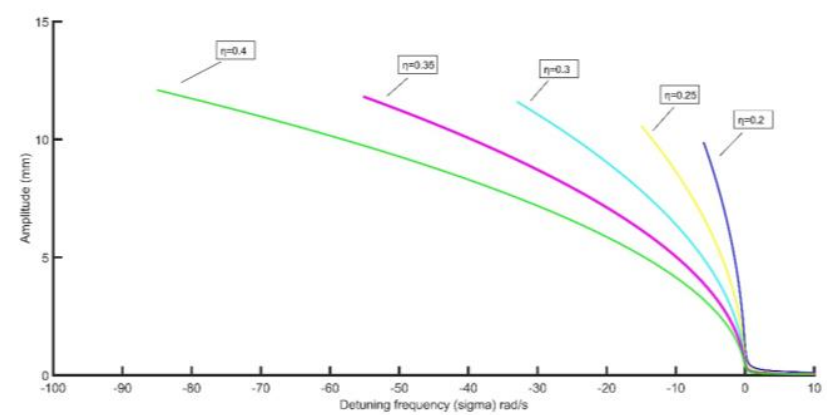

Fig. 2. The impact of position change on nonlinear frequency curve when $\zeta=0.35, \psi=0.001$, and $F_{1,2}=250 \mathrm{~N}$

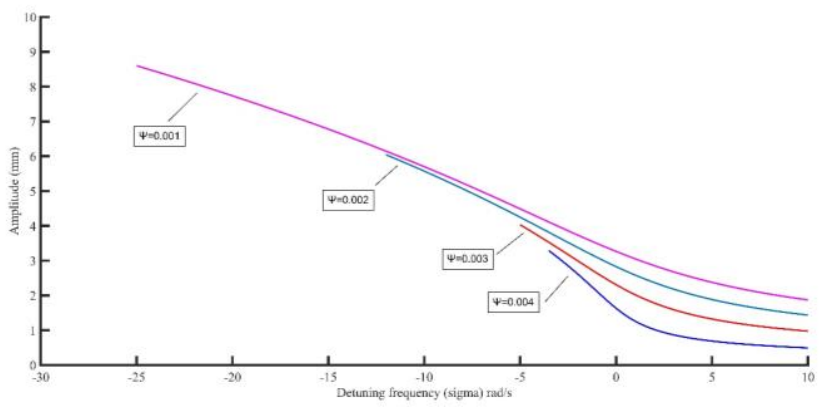

Fig. 3. The impact of damping change on nonlinear frequency curve when $\eta=0.25, \zeta=0.18$,

$$
\text { and } F_{1,2}=200 \mathrm{~N}
$$




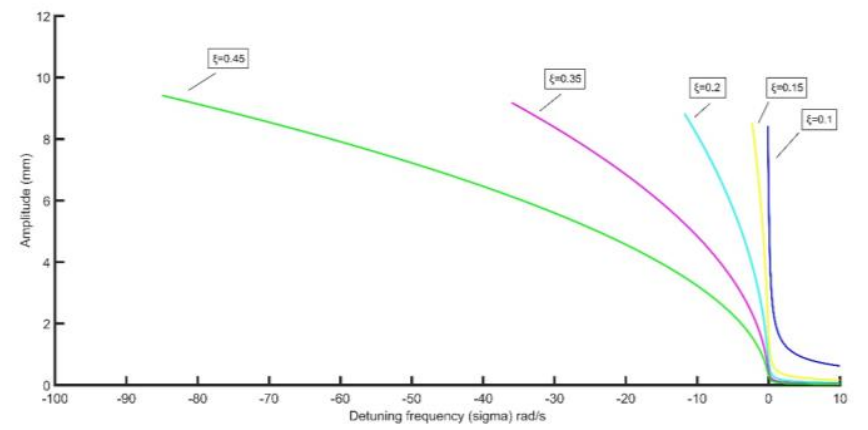

Fig. 4. The impact of crack depth change on nonlinear frequency curve when $\eta=0.25, \psi=0.001$,

$$
\text { and } F_{1,2}=200 \mathrm{~N}
$$

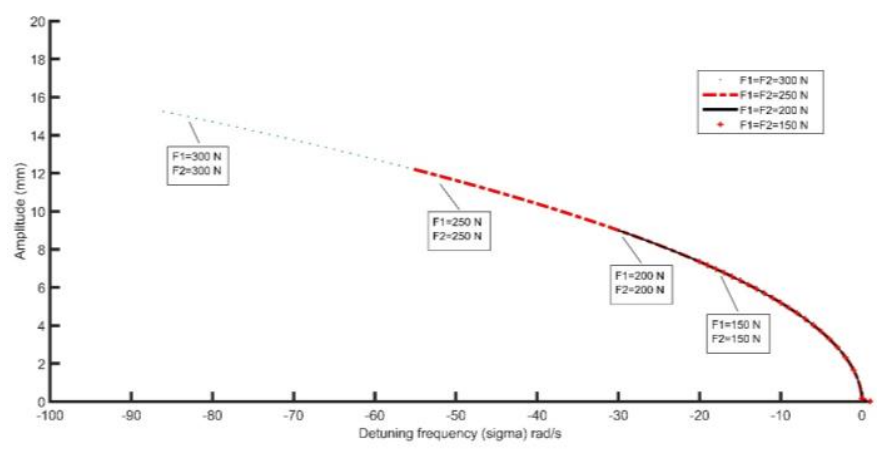

Fig. 5. The impact of forces magnitude change on nonlinear frequency curve when $\eta=0.25, \zeta=0.35$,

$$
\psi=0.001 \text {, and } \Omega_{1,2}=150 \mathrm{rad} / \mathrm{sec}
$$

By comparing Figs. 6 and 7, it seems that using multiple frequency excitations leads to a difference in sensitivity by comparing the excitations considering equal magnitudes for force and frequency. In these studies, the total sum of excitations and frequencies is constant to have a better comparable situation.

As can be seen in Fig. 6, two different forces amplitude of $600 \mathrm{~N}$ and $20 \mathrm{~N}$, considering the same frequencies of $150 \mathrm{rad} / \mathrm{sec}$ are plotted. Then by the same forces of $600 \mathrm{~N}$ and $20 \mathrm{~N}$, the frequencies are changed to $100 \mathrm{rad} / \mathrm{sec}$ and $200 \mathrm{rad} / \mathrm{sec}$. The lower frequency is assigned to the stronger excitation and the higher one assigned to the weaker force. The result shows that the sensitivity has increased. Due to the same detuning frequency, the magnitude of the amplitude of the vibration has increased. Therefore, this kind of approach leads to a more sensitive nonlinear behaviour of cracked beams that is a significant issue in the crack detection and structural health monitoring application.

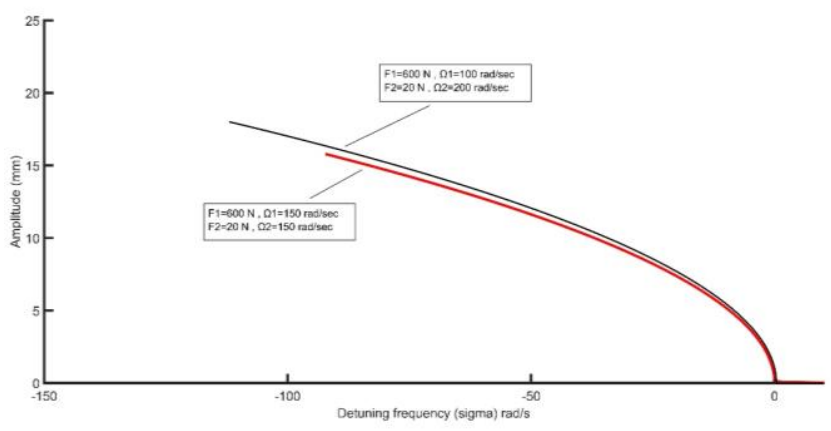

Fig. 6. The impact of frequencies changes on nonlinear frequency curve when $\eta=0.25, \zeta=0.35$, and

$$
\psi=0.001
$$

The result of changing frequencies magnitude has been a positive influence on the sensitivity of the cracked beam analysis. As shown in Fig. 7, a $600 \mathrm{~N}$ force with zero frequency (constant force) in the role of pre-force and a 20 $\mathrm{N}$ force with a frequency of $300 \mathrm{rad} / \mathrm{sec}$ are applied. Note that, like the previous analysis that the total sum of the excitations in magnitude and frequency was constant, this assumption is valid during pre-force and harmonic excitation analysis.

By comparing the response of multiple excitations, which is significant in Fig. 7, the result shows that excitation with a constant pre-force could increase the sensitivity of the crack analysis in nonlinear frequency curves again. In this figure, in the same detuning frequency, the magnitude of the amplitude of the vibration has increased again to result in the values indicated in Fig. 6.

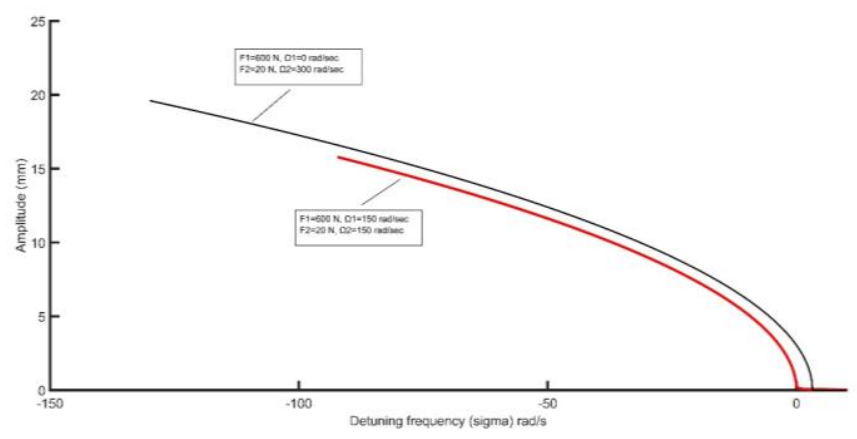

Fig. 7. The impact of pre-force and changing frequencies on nonlinear frequency curve when $\eta=0.25$, and

$$
\psi=0.001
$$

\section{CONCLUSIONS}

In this paper, a nonlinear cracked Euler-Bernoulli beam with a single degree of freedom under multiple excitations with multi-frequencies has been studied. Applying multiple frequency excitations lead to some combinational resonances. One of these resonances is 
employed to study the nonlinear behaviour of the cracked beam. By using the method of multiple time scales in a combination resonance, the equation of the motion of the cracked beam has been derived and solved. The results show that the analysis of crack parameters in the nonlinear vibration of multiple excitations may be a suitable method for identifying the crack and the depth of the damage for structural health monitoring applications. In this study, we analyzed the effects of multiple-loads with different or the same frequencies on a cracked beam. The total sum of magnitudes and frequencies during the study of their effect is constant. The result shows that if a higher frequency assigned to a weaker force, the sensitivity of the nonlinear frequency responses increases. In this condition, in the same detuning frequency, we have a higher vibration magnitude. Then we decrease the frequency of stronger force to zero and increase the frequency of weaker force. In this condition, the stronger force has appeared in the role of the constant force or pre-force. It was observed that the sensitivity was increased again. The results indicate that the multiple frequency excitations lead to more sensitivity on nonlinear vibration responses of cracks. Based on the analytical results, a pre-force with a simple harmonic excitation can be more sensitive than a simple harmonic excitation to demonstrate a cracked beam's behaviour. Therefore, the results have indicated that the multi-frequency excitations model has introduced an effective method in structural health monitoring in order to study the vibrational nonlinearities of cracked beams.

\section{REFERENCES}

[1] Motamedi, M. \& Hashemi, R. (2021). "Evaluation of Temperature Effects on Forming Limit Diagrams of AA6061-T6 Considering the Marciniak and Kuczynski Model," Journal of Testing and Evaluation 49 (in press). https://doi.org/10.1520/JTE20190011.

[2] Motamedi, M. A., Sarbaz Sara, Irani Saied, \& Masoud Kharazan (2018). Nonlinear vibration analysis of cracked beam under multiple frequency excitations. 8th International Conference on Acoustics and Vibration, Shahid Beheshty University, Tehran, Iran.

[3] Sarbaz Sara, Motamedi, M. A., Irani Saied, \& Masoud Kharazan (2018). Crack detection in cantilever beam using nonlinear vibration of multiple frequency excitations. 8th International Conference on Acoustics and Vibration, Shahid Beheshty University, Tehran, Iran.

[4] Narkis, Y. (1994). Identification of crack location in vibrating simply supported beams. Journal of sound and vibration, 172(4), 549-558.

https://doi.org/10.1006/jsvi.1994.1195

[5] Lee, J. W. (2016). Crack identification method for tapered cantilever pipe-type beam using natural frequencies. International Journal of Steel Structures, 16(2), 467-476.

https://doi.org/10.1007/s13296-016-6017-x

[6] Khiem, N. T., \& Toan, L. K. (2014). A novel method for crack detection in beam-like structures by measurements of natural frequencies. Journal of Sound and Vibration, 333(18), 4084-4103. https://doi.org/10.1016/j.jsv.2014.04.031

[7] Khiem, N. T., \& Tran, H. T. (2014). A procedure for multiple crack identification in beam-like structures from natural vibration mode. Journal of Vibration and Control, 20(9), 1417-1427. https://doi.org/10.1177/1077546312470478

[8] Ganguli, R., \& Gouravaraju, S. (2016). Damage detection in cantilever beams using spatial Fourier coefficients of augmented modes. Proceedings of the Institution of Mechanical Engineers, Part C: Journal of Mechanical Engineering Science, 230(20), 36773690. https://doi.org/10.1177/0954406215616419

[9] Panigrahi, B., \& Pohit, G. (2018). Effect of cracks on nonlinear flexural vibration of rotating Timoshenko functionally graded material beam having large amplitude motion. Proceedings of the Institution of Mechanical Engineers, Part C: Journal of Mechanical Engineering Science, 232(6), 930-940. https://doi.org/10.1177/0954406217694213

[10] Ballo, I. (1998). Non-linear effects of vibration of a continuous transverse cracked slender shaft. Journal of sound and vibration, 217(2), 321-333. https://doi.org/10.1177/0954406217694213

[11] Curadelli, R. O., Riera, J. D., Ambrosini, D., \& Amani, M. G. (2008). Damage detection by means of structural damping identification. Engineering Structures, 30(12), 3497-3504.

https://doi.org/10.1016/j.engstruct.2008.05.024

[12] Eroglu, U., \& Tufekci, E. (2016). Exact solution based finite element formulation of cracked beams for crack detection. International Journal of Solids and Structures, 96, 240-253. https://doi.org/10.1016/j.ijsolstr.2016.06.005

[13] Dixit, A., \& Hanagud, S. (2011). Single beam analysis of damaged beams verified using a strain energy based damage measure. International Journal of Solids and Structures, 48(3-4), 592-602. https://doi.org/10.1016/j.ijsolstr.2010.10.025

[14] Çam, E., Orhan, S., \& Lüy, M. (2005). An analysis of cracked beam structure using impact echo method. Ndt \& E International, 38(5), 368-373. https://doi.org/10.1016/j.ndteint.2004.10.009

[15] Friswell, M. I., \& Penny, J. E. (2002). Crack modeling for structural health monitoring. Structural health monitoring, 1(2), 139-148. https://doi.org/10.1177/1475921702001002002

[16] Douka, E., Bamnios, G., \& Trochidis, A. (2004). A method for determining the location and depth of cracks in double-cracked beams. Applied acoustics, 65(10), 997-1008. 
International Journal of Advanced Engineering, Sciences and Applications (IJAESA), Volume 1, Issue 1, January 2020

https://doi.org/10.1016/j.apacoust.2004.05.002

[17] Jassim, Z. A., Ali, N. N., Mustapha, F., \& Jalil, N. A. (2013). A review on the vibration analysis for a damage occurrence of a cantilever beam. Engineering Failure Analysis, 31, 442-461. https://doi.org/10.1016/j.engfailanal.2013.02.016

[18] Heydari, M., Ebrahimi, A., \& Behzad, M. (2015). Continuous model for flexural vibration analysis of Timoshenko beams with a vertical edge crack. Archive of Applied Mechanics, 85(5), 601-615. https://doi.org/10.1007/s00419-014-0933-z

[19] Balci, M., \& Gundogdu, O. (2017). Estimation of physical properties of laminated composites via the method of inverse vibration problem. Journal of Mechanical Science and Technology, 31(1), 29-36. https://doi.org/10.1007/s12206-016-1204-4

[20] Bachschmid, N., Pennacchi, P., Tanzi, E., \& Vania, A. (2000). Identification of transverse crack position and depth in rotor systems. Meccanica, 35(6), 563582. https://doi.org/10.1023/A:1010562205385

[21] Krawczuk, M., \& Ostachowicz, W. M. (1995). Modelling and vibration analysis of a cantilever composite beam with a transverse open crack. Journal of Sound and Vibration, 183(1), 69-89. https://doi.org/10.1006/jsvi.1995.0239

[22] Gudmundson, P. (1983). The dynamic behaviour of slender structures with cross-sectional cracks. Journal of the Mechanics and Physics of Solids, 31(4), 329345. https://doi.org/10.1016/0022-5096(83)90003-0

[23] Orhan, S. (2007). Analysis of free and forced vibration of a cracked cantilever beam. Ndt \& $E$ International, 40(6), 443-450. https://doi.org/10.1016/j.ndteint.2007.01.010

[24] Ostachowicz, W. M., \& Krawczuk, M. (1991). Analysis of the effect of cracks on the natural frequencies of a cantilever beam. Journal of sound and vibration, 150(2), 191-201. https://doi.org/10.1016/0022-460X(91)90615-Q

[25] Papadopoulos, C. A., \& Dimarogonas, A. D. (1987). Coupled longitudinal and bending vibrations of a rotating shaft with an open crack. Journal of sound and vibration, 117(1), 81-93. https://doi.org/10.1016/0022-460X(87)90437-8

[26] Wu, D., \& Law, S. S. (2004). Anisotropic damage model for an inclined crack in thick plate and sensitivity study for its detection. International journal of solids and structures, 41(16-17), 43214336. https://doi.org/10.1016/j.ijsolstr.2004.03.001

[27] Prawin, J., \& Rao, A. R. M. (2019). Nonlinear System Identification of Breathing Crack Using Empirical Slow-Flow Model. In Recent Advances in Structural Engineering, Volume 1 (pp. 1075-1085). Springer, Singapore. https://doi.org/10.1007/978-981-13-03623_85

[28] Lengyel, G., \& Németh, R. K. (2018). Symmetric free vibration of a cracked, quasi-continuous, masonry arch. Meccanica, 53(4-5), 1071-1091. https://doi.org/10.1007/s11012-017-0776-0

[29] Neves Carneiro, G., \& Ribeiro, P. (2016). Vibrations of beams with a breathing crack and large amplitude displacements. Proceedings of the Institution of Mechanical Engineers, Part C: Journal of Mechanical Engineering Science, 230(1), 34-54. https://doi.org/10.1177/0954406215589333

[30] Caddemi, S., Caliò, I., \& Marletta, M. (2010). The non-linear dynamic response of the Euler-Bernoulli beam with an arbitrary number of switching cracks. International Journal of Non-Linear Mechanics, 45(7), 714-726.

https://doi.org/10.1016/j.ijnonlinmec.2010.05.001

[31] Bolotin, V. V., \& Shipkov, A. A. (2001). Mechanical aspects of corrosion fatigue and stress corrosion cracking. International Journal of Solids and Structures, 38(40-41), 7297-7318. https://doi.org/10.1016/S0020-7683(01)00002-6

[32] Fu, C., Ren, X., Yang, Y., Lu, K., \& Wang, Y. (2018). Nonlinear response analysis of a rotor system with a transverse breathing crack under interval uncertainties. International Journal of Non-Linear Mechanics, 105, 77-87.

https://doi.org/10.1016/j.ijnonlinmec.2018.07.001

[33] Cicirello, A., \& Palmeri, A. (2014). Static analysis of Euler-Bernoulli beams with multiple unilateral cracks under combined axial and transverse loads. International Journal of Solids and Structures, 51(5), 1020-1029.

https://doi.org/10.1016/j.ijsolstr.2013.11.030

[34] Giannopoulos, G. I., Georgantzinos, S. K., \& Anifantis, N. K. (2015). Coupled vibration response of a shaft with a breathing crack. Journal of Sound and Vibration, 336, 191-206.

https://doi.org/10.1016/j.jsv.2014.09.037

[35] Wauer, J. (1990). Modelling and formulation of equations of motion for cracked rotating shafts. International Journal of Solids and Structures, 26(8), 901-914. https://doi.org/10.1016/0020-7683(90)90076-8

[36] Ogam, G., Groby, J. P., \& Ogam, E. (2014). A nonlinear vibration spectroscopy model for structures with closed cracks. International Journal of Non-Linear Mechanics, 59, 60-68. https://doi.org/10.1016/j.ijnonlinmec.2013.11.003

[37] Liu, W., \& Barkey, M. E. (2017). Nonlinear vibrational response of a single edge cracked beam. Journal of Mechanical Science and Technology, 31(11), 5231-5243. https://doi.org/10.1007/s12206-017-1016-1

[38] Liu, W., \& Barkey, M. E. (2018). The effects of breathing behaviour on crack growth of a vibrating beam. Shock and Vibration, 2018. https://doi.org/10.1155/2018/2579419

[39] Ke, L. L., Yang, J., \& Kitipornchai, S. (2010). An analytical study on the nonlinear vibration of 
functionally graded beams. Meccanica, 45(6), 743752. https://doi.org/10.1007/s11012-009-9276-1

[40] Zhang, D. G. (2014). Thermal post-buckling and nonlinear vibration analysis of FGM beams based on physical neutral surface and high order shear deformation theory. Meccanica, 49(2), 283-293. https://doi.org/10.1007/s11012-013-9793-9

[41] Shegokar, N. L., \& Lal, A. (2014). Stochastic finite element nonlinear free vibration analysis of piezoelectric functionally graded materials beam subjected to thermo-piezoelectric loadings with material uncertainties. Meccanica, 49(5), 1039-1068. https://doi.org/10.1007/s11012-013-9852-2

[42] Andreaus, U., \& Baragatti, P. (2011). Cracked beam identification by numerically analysing the nonlinear behaviour of the harmonically forced response. Journal of Sound and Vibration, 330(4), 721-742. https://doi.org/10.1016/j.jsv.2010.08.032

[43] Andreaus, U., Casini, P., \& Vestroni, F. (2007). Nonlinear dynamics of a cracked cantilever beam under harmonic excitation. International journal of nonlinear mechanics, 42(3), 566-575.

https://doi.org/10.1016/j.ijnonlinmec.2006.08.007

[44] M. Lalanne, P. Berthier and J. D. Hagopian, (1983), Mechanical vibrations for engineers, Wiley, New York.

[45] Clough, R. W., and J. Penzien. (1993), Dynamics of Structures. McGraw Hill, New York.

[46] Dimarogonas, A. D., Paipetis, S. A., \& Chondros, T. G. (2013). Analytical methods in rotor dynamics. Springer Science \& Business Media.

[47] Nayfeh, A. H. (2011). Introduction to perturbation techniques. John Wiley \& Sons, New York. 